\title{
Tudo junto e misturado - como explorar a diversidade de conhecimentos em turmas iniciantes?
}

\author{
Rita C. G. Berardi ${ }^{1,2}$, Silvia Amélia Bim ${ }^{1}$ \\ ${ }^{1}$ Departamento Acadêmico de Informática $-{ }^{2}$ Programa de Pós Graduação em Computação \\ Aplicada (PPGCA) \\ Universidade Tecnológica Federal do Paraná (UTFPR) - Curitiba, PR- Brasil \\ \{ritaberardi, sabim\} Cutfpr.edu.br
}

\begin{abstract}
The profile of freshman classes in computer courses has changed over the years, with students who already program together with students who never programmed and therefore have a different learning curve. Therefore, it is necessary to discuss methodologies that can exploit this difference in knowledge in order to develop each student from their particular point of knowledge. This article aims to report the experience of using Unplugged Computing techniques supported by Social Learning theory as an alternative.
\end{abstract}

Resumo. O perfil das turmas de primeiro período em cursos de computação tem se modificado ao longo dos anos, tendo estudantes que já programam junto com estudantes que nunca programaram e por isso possuem uma curva de aprendizado diferente. Sendo assim, é necessário que se discuta sobre metodologias que consigam explorar essa diferença de conhecimento de forma a desenvolver cada estudante a partir do seu ponto particular de conhecimento. Este artigo tem como objetivo relatar a experiência do uso de técnicas de Computação Desplugada apoiadas pela teoria de aprendizagem Social Learning como uma alternativa para explorar essa diversidade.

\section{Introdução}

O ensino de Programação para estudantes ingressantes nos cursos de computação traz muitos desafios já conhecidos e estudados pela comunidade há algum tempo, como afirma Giraffa e Mora (2013). Muito se fala sobre as dificuldades relacionadas a uma base fraca ou até insuficiente de conhecimentos matemáticos e de raciocínio lógico exigidos em disciplinas iniciais de programação. Todas essas dificuldades trazem relevante impacto na formação de cada estudante, desde uma curva maior de aprendizado até a própria evasão. No entanto, outro aspecto também presente nas turmas de iniciantes, que acrescenta uma importante complexidade ao ensino de programação é a heterogeneidade de conhecimento sobre programação entre os estudantes. O perfil das turmas de iniciantes em cursos superiores de computação tem se modificado ao longo dos anos, pelas características inerentes das novas gerações [Viana et al 2019]. Além da maior oferta de cursos de Informática em nível técnico no Ensino Médio, que faz com que muitos estudantes já cheguem no curso superior de computação com uma boa bagagem de programação, também deve-se considerar aqueles que aprendem de forma autodidata. Sendo assim, docentes de disciplinas de programação para turmas de ingressantes necessitam de metodologias adequadas para explorar de maneira produtiva esta heterogeneidade. Em metodologias em que a aprendizagem é socialmente elaborada (Social Learning) [Vygotsky e Cole 1978], essa heterogeneidade de conhecimentos passa a ser uma vantagem ao invés 
de um aparente problema, uma vez que a interação entre estudantes será estrategicamente mediada com foco no desenvolvimento. Segundo Vygotsky a aprendizagem é, além de um processo individual, também social. Docentes ao não reconhecerem as diversas maneiras que estudantes mais experientes podem compartilhar seu conhecimento com estudantes menos experimentes, podem limitar o desenvolvimento intelectual de ambos perfis [Vygotsky e Cole, 1978, p. 126]. Além do aspecto cognitivo, utilizar uma metodologia de ensino que não considere esta heterogeneidade pode desmotivar quem já possui parte do conhecimento ou ainda não dar o suporte necessário a quem precisa nesta fase inicial.

Estudos como o de Reis et al (2018) têm observado um impacto positivo do uso de metodologias como Computação Desplugada [Bell, Witten e Fellows 2011] à luz de conceitos de teorias de aprendizagens adequadas. No entanto, pouco tem se explorado essas técnicas ligadas ao problema da heterogeneidade de conhecimento prévio nas turmas iniciais. O estudo de Viana et al (2019) conclui que este tipo de iniciativa deve ser explorada por ter percebido uma relação entre o conhecimento de programação prévio à entrada no curso, com o bom desempenho nas disciplinas. Fragelli e Fragelli (2017) criaram a metodologia "Trezentos" para promover aprendizagem colaborativa em turmas de Cálculo I para iniciantes em cursos de Engenharia e inspirou a dinâmica aqui apresentada. Este artigo tem como objetivo relatar a experiência da aplicação de Social Learning em atividades inspiradas em Computação Desplugada [Bell, Witten e Fellows 2011], mostrando a percepção de estudantes sobre o impacto desta metodologia na sua formação no início de um curso de Computação.

\section{Descrição da experiência}

A experiência relatada foi realizada na disciplina Prolegômenos ao Computar, do $1^{\circ}$ semestre do curso de Bacharelado em Sistemas de Informação. Esta disciplina é composta por estudantes que ingressam pela primeira vez em um curso superior sem conhecimento em programação, por estudantes que optam por transferência de universidade ou de curso, e por estudantes que cursaram Ensino Médio integrado com curso técnico em Informática. A ementa desta disciplina compreende desde Pensamento Computacional até discussões de Aspectos éticos e sociais da Computação. A abordagem de Pensamento Computacional é o primeiro conteúdo abordado e abrange um terço do tempo da disciplina. A prática de atividades inspiradas no conceito de Computação Desplugada com Social Learning é enfatizada neste primeiro conteúdo justamente pelo possível impacto causado pela heterogeneidade de conhecimentos da turma. A metodologia foi utilizada nos dois semestres do ano letivo 2019, entretanto a coleta de feedback de estudantes foi realizada em apenas uma das turmas, composta por 48 estudantes, cuja experiência será descrita neste artigo.

\subsection{Preparação}

Na primeira aula da disciplina a turma foi avisada sobre o uso de uma metodologia de colaboração social para o conteúdo de Pensamento Computacional e consequentemente sobre a atividade da aula seguinte que tinha como objetivo identificar o nível de conhecimento sobre programação de cada estudante. O desempenho na atividade poderia indicar um, dentre dois perfis: Estudex e Prolex. O perfil Estudex foi usado para classificar estudantes na fase "Expert em Estudar". O perfil Prolex, por sua vez, indicava estudantes em uma fase mais avançada "Expert em Prolegômenos". A nomenclatura foi propositadamente personalizada para o contexto da disciplina para tentar despertar mais 
interesse e "sensação de pertencimento" em cada estudante. A intenção foi evitar termos já conhecidos e carregados de "preconceitos" como tutor ou líder.

\subsection{Definição dos perfis}

A atividade que identificou Estudex e Prolex foi composta por questões envolvendo conceitos de entrada/processamento/saída, estruturas condicionais e de repetição, vetores e matrizes. É importante salientar que as questões eram teóricas ou utilizavam fluxogramas como linguagem, para evitar valorizar qualquer conhecimento de linguagem de programação e assim identificar a lógica do pensamento computacional. Ao final da atividade cada estudante deveria se autoidentificar como Estudex ou como Prolex. Na autodeclaração uma pessoa se identificou como Prolex, mas não conseguiu demonstrar na atividade todo seu conhecimento. O contrário também aconteceu quando uma pessoa se declarou Estudex, mas demonstrava um conhecimento suficiente para ser Prolex. Nestas situações, a professora conversou com cada estudante. O perfil de Prolex foi atribuído nos dois casos mas quem se identificou como Prolex sem demonstrar conhecimento, a professora salientou que a responsabilidade em assumir o papel seria do estudante. Foram criados 12 grupos com 1 Prolex e 3 Estudex cada.

\subsection{Dinâmica das aulas}

A proposta foi reunir grupos que de forma colaborativa pudessem desenvolver diferentes habilidades respeitando seu "status de conhecimento atual". Pessoas com algum conhecimento prévio (Prolex) teriam a oportunidade de desenvolver outras habilidades, além de técnicas, ao colaborar com o desenvolvimento de integrantes do perfil Estudex. Por outro lado, Estudex poderiam contar no seu desenvolvimento técnico com uma pessoa que usa uma linguagem mais próxima da sua e com uma atenção maior, pois em grandes turmas a atenção docente é dividida em intervenções mais rápidas para atender a todas as demandas. As atividades que o grupo deveria realizar foram propostas em sala de aula com dinâmicas sem uso do computador (desplugadas) e cada perfil tinha um conjunto de regras (Tabela 1). Ambos perfis devem fazer a prova individual como avaliação desta Etapa 1.

Tabela 1: Regras de acordo com cada perfil

\begin{tabular}{|c|c|c|}
\hline & Estudex & Prolex \\
\hline $\begin{array}{l}\text { Habilidades a } \\
\text { serem } \\
\text { desenvolvidas }\end{array}$ & $\begin{array}{l}\text { - Pensamento Computacional } \\
\text { - Colaboração }\end{array}$ & $\begin{array}{l}\text { - Colaboração } \\
\text { - Comunicação } \\
\text { - Empatia } \\
\text { - Pró-atividade }\end{array}$ \\
\hline $\begin{array}{l}\text { Responsabilidades } \\
\text { durante as aulas }\end{array}$ & $\begin{array}{l}\text { - Registrar no papel os exercícios } \\
\text { propostos } \\
\text { - Colaborar com colegas pedindo } \\
\text { ou oferecendo auxílio } \\
\text { - Prover feedback para Prolex }\end{array}$ & $\begin{array}{l}\text { - Auxiliar Estudex durante o } \\
\text { registro no papel dos } \\
\text { exercícios } \\
\text { - Prover feedback para } \\
\text { Estudex }\end{array}$ \\
\hline $\begin{array}{l}\text { Recuperação da } \\
\text { Etapa } 1\end{array}$ & $\begin{array}{l}\text { - Conjunto de exercícios } \\
\text { carimbados em sala de aula pela } \\
\text { professora }\end{array}$ & $\begin{array}{l}\text { - Conjunto de feedbacks } \\
\text { positivos de Estudex do } \\
\text { grupo }\end{array}$ \\
\hline Prêmio & \multicolumn{2}{|c|}{ Se todos do grupo alcançarem nota mínima 7} \\
\hline
\end{tabular}


na Prova da Etapa 1 , soma-se 0.5 na nota da etapa 1

É importante salientar que se buscou, com essas regras específicas fazer com que a aprendizagem social de fato acontecesse. $\mathrm{O}$ fato de reunir estudantes em grupo, não garante a sua colaboração. Para isso cada estudante, de acordo com seu perfil deveria buscar, através das regras, desenvolver o que foi proposto. Para cada perfil houve um tipo de recompensa diferente. Para o perfil Prolex valorizou-se a qualidade da colaboração com seu grupo, estando dispensado de entregar exercícios, que em algum nível, ele já sabe. Para o perfil Estudex a valorização está no seu esforço em realizar as atividades propostas em sala de aula, com a chance de receber o "carimbo de participação" da professora e assim acumular seu possível ponto de recuperação. Estudex e Prolex dão feedbacks sobre a experiência (colaboração e esforço, respectivamente) em cada aula através de um formulário online disponibilizado pela professora. Apenas a professora tem acesso aos feedbacks, e ela possui a tarefa de repassar os feedbacks promovendo reconciliações e entendimentos entre o grupo, quando necessário. Nesta turma não foi necessária nenhuma intervenção em grupos por feedbacks negativos demais. A recompensa para o grupo promove um maior engajamento de cada estudante.

\section{Resultados e Discussão}

A atividade de nivelamento não tem o objetivo de identificar estudantes que "passariam" ou "gabaritariam" caso ela fosse uma prova. Mas sim, identificar quem possui conhecimento suficiente para auxiliar outra pessoa que ainda não tem esse conhecimento, mas também não tão suficiente que não precise de um aprimoramento ou lapidação. Por exemplo, havia uma questão teórica que questionava para um determinado problema, se seria necessário utilizar uma estrutura de repetição, e se sim, deveria dizer qual seria a melhor estrutura e porquê. Algumas pessoas com perfil Prolex erraram em apontar qual era a melhor estrutura de repetição, porém, acertaram em afirmar que seria necessário o seu uso e a justificativa para isto. Neste caso, é visível que tal estudante tem um conhecimento prévio, mas que precisa ser aprimorado. Se por um lado, ignorar que ele possui este conhecimento pode ser bastante desmotivador, por outro, valorizar o que ele já tem, mesmo que imperfeito, pode motivá-lo ainda mais a buscar o seu melhor. A maioria de Estudex, em questões como esta respondeu "não sei o que é uma estrutura de repetição".

A metodologia foi analisada: i) comparando o desempenho da turma e percentual de desistência com turmas anteriores e ii) coletando a opinião da turma sobre o impacto da metodologia no desenvolvimento de cada estudante, por meio de um questionário disponibilizado no final do semestre. O questionário foi respondido por 22 estudantes ,15 Estudex (do total de 36) e 7 Prolex (do total de 12). Observando a Figura 1(a), é possível visualizar uma sutil redução tanto em reprovação quanto desistência entre o ano de 2018 (em que essa metodologia não foi utilizada) e 2019 em que ambas turmas praticaram a metodologia.

Para o perfil Estudex foram feitas três perguntas. Na Figura 1(b) pode-se observar um feedback positivo para a primeira questão (Quanto você acredita que fazer parte deste grupo com diferentes perfis ajudou a motivar a aprender os conteúdos e ajudou a aprender de fato?) podendo-se notar uma maior motivação do que uma percepção de aprendizado.

Para a segunda pergunta (Quanto o papel de Estudex te ajudou a se sentir acolhido(a) durante as aulas?) a maioria sinalizou que a metodologia ajudou muito na percepção de acolhimento. Tal percepção pode ter influenciado a resposta para a terceira 
questão (Quanto você acredita que participar deste grupo como Estudex ajudou a não desistir do curso?) pois a maioria respondeu que não pensou em desistir do curso.
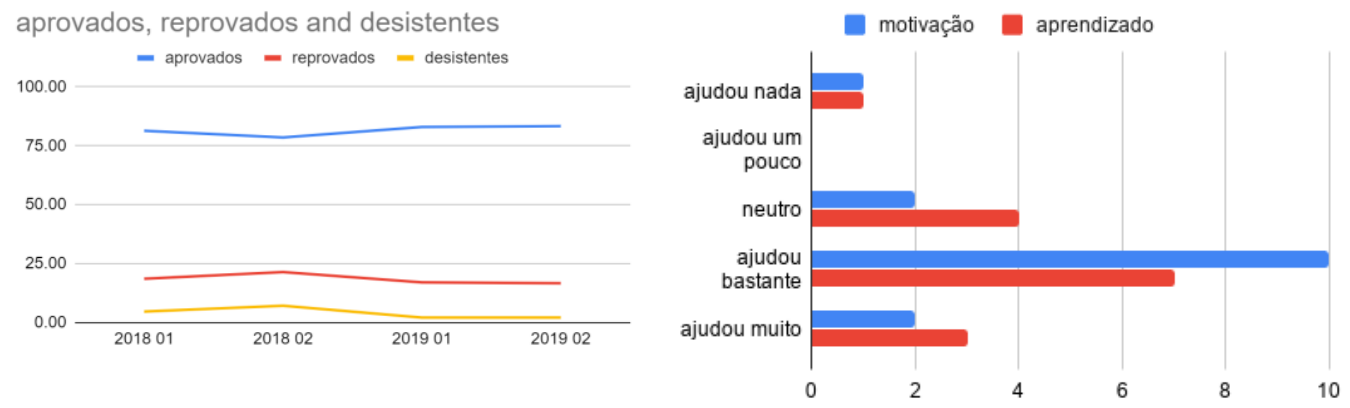

Figura 1: (a) Desempenho e desistência; (b) Motivação e Aprendizado para Estudex

Para a pergunta feita ao perfil Prolex "quanto participar deste grupo como Prolex te motivou a ser mais participativo (a) na disciplina?" nenhum estudante sinalizou que não motivou em nada.

\section{Conclusão}

A análise dos resultados da experiência relatada com uma turma de ingressantes, mostra uma alternativa para uma situação recorrente mas ainda pouco explorada: heterogeneidade de conhecimentos em turmas de calouros. O conceito de Social Learning aliado às atividades de Computação Desplugada fez com que o trabalho em grupo atenuasse a diferença de conhecimento entre os estudantes, proporcionando assim o desenvolvimento de diferentes habilidades de acordo com os diferentes perfis. Em comparação com turmas anteriores que não usaram a metodologia, a grande vantagem foi a diminuição do número de desistências. Apesar da amostra não permitir generalizações, espera-se que este relato traga a possibilidade de replicabilidade da experiência para fins de discussão sobre a viabilidade e efetividade da metodologia em outras turmas semelhantes.

\section{Referências}

Bell, T., Witten, I., Fellows, M. (2011). "Computer Science Unplugged - Ensinando Ciência da Computação sem o uso do Computador”. Tradução de Luciano Porto Barreto.

Fragelli, R. R., \& Fragelli, T. B. O. (2017). Trezentos: a dimensão humana do método. Educar em Revista, (63), 253-265.

Giraffa, L. M. M.; Mora, M. C. (2013). Evasão na Disciplina de Algoritmo e Programação: Um Estudo a Partir dos Fatores Intervenientes na Perspectiva do Aluno. In: III Conferencia Sobre el Abandono en la Educación Superior (Iii Clabes), v. 3, 2013, Espanha.

Reis, R., Lyra. K, Reis, C. e Isotani, S. (2018) Relato de Experiência sobre o uso da Computação Desplugada associada a uma Teoria de Aprendizagem Colaborativa. Anais do Workshop de Informática na Escola, [S.1.], p. 166.

Vygotsky, L.S., Cole, M. (1978) Mind in Society: The development of higher psychological processes. Cambridge, MA: Harvard University Press.

Viana, G., Lopes, A., Portela, C., Oliveira, S. (2019). Um Survey sobre a Aprendizagem de Programação no Curso de Sistemas de Informação. In: Workshop Sobre Educação em Computação (WEI), 27. , 2019, Belém. 